that they were relieved that they were not alone in experiencing such feelings. Attempts were made to get the fathers to take part in the discussions and to help the couple share their grief, though this was often difficult.

\section{Discussion}

Although we approached this work with some trepidation and feelings of helplessness at the thought of trying to ameliorate such suffering, we were constantly encouraged by the parents' gratitude at our intervention. As our work progressed families were referred to us who had experienced a sudden infant death some years previously and were still having problems, sometimes caused by the birth of a subsequent child.

Our conclusion from this initial study is that positive support should be offered to all families with babies that have died suddenly. Social workers in hospitals are well placed to link parents with local support groups, health visitors, general practitioners, and a paediatrician in the hospital. We have little doubt that an interview with a sympathetic, informed doctor is an important step for many parents in coming to terms with their loss. The health visitor was often in an ideal position, but regular support depended on whether a good relationship already existed. The work can be quite stressful, and, as Watson pointed out, not everyone is temperamentally suited to it. ${ }^{4}$ The sudden infant death syndrome is still fairly rare, so perhaps health visitors interested in working with bereaved couples should be identified and receive extra training and support. Bereavement counselling for trainee general practitioners could include specific guidance on the sudden infant death syndrome. For doctors, health visitors, and social workers the success of any help given is likely to depend on the helper's confidence that parents will value the support offered.

\section{References}

1 Knight B. Sudden death in infancy; the "cot death" symdrome. London: Faber and Faber, 1983:16Blugiass K. Psychintric morbidity after cot death. Practitioner 1980;224:533-9. 2 Bluglass K. Psychiatric morbidity after cot death. Pracritioner 1980;224:533

3 Williams ML. Sibling reaction to cot death. Med $f$ Aust 1981;2:227-31. Watson E, Gardner A, Carpenter RG. An epidemiological and sociological study of uncto death in infancy in nine areas of southern England. Med Sci Laro 1981;21(ii):89-98.

6 Murray-Parkes C. Bereavement-studies of grief in adula hife. Middlesex: Pelican, 1975.

7 DeFrain J, Taylor J, Ernst L. Coping with sudden infant death. Massachusetts: Lexington Books, 1982.

(Accepted 23 October 1984)

\title{
Product liability in respect of drugs
}

\author{
A L DIAMOND, D R LAURENCE
}

English law has for many years contained principles which enable persons injured by defective goods or products in certain circumstances to receive a money payment from another person. These principles apply to injuries caused by drugs as well as by any other product, though their application to drugs raises several special problems.

The law evolved in a pragmatic way and followed two separate lines of development. One concentrated on the immediate relationship between seller and buyer, there being a contract between them-which can be quite informal: there is a contract of sale of goods between a retail pharmacist and a customer who buys a bottle of aspirin. The other line concentrated on a duty to be careful owed by one person to another and does not depend on a direct contractual relationship.

\section{Supply contracts}

Not many cases arising from the sale of pharmaceutical products have come to court, but some important decisions have been made in cases concerning food or drink. Thus in one case (Frost $v$ Aylesbury Dairy Co in 1905) milk supplied by a dairy caused the death of a Mrs Frost by typhoid. The dairy was sued for breach of the implied condition under the Sale of Goods Act 1893, then in force, that the milk would be reasonably fit for the purpose for which it was bought-namely, for human consumption. In its defence the dairy argued that it had taken every precaution possible in the then state of scientific knowledge to prevent infection, but the court said that this was irrelevant. Whether or not it was guilty of fault or negligence was

Institute of Advanced Legal Studies, University of London, London WC1B 5DR A L DIAMOND, LLM, professor of law and director

School of Medicine, University College London, London WC1E 6JJ D R LAURENCE, MD, FRCP, professor of pharmacology and therapeutics

Correspondence to: Professor D R Laurence. beside the point. Liability of this kind, where fault is irrelevant, is sometimes known as "strict liability."

There is an important limitation on these liabilities under the modern Sale of Goods Act 1979. Remedies under the Act are open only to the individual buyer who has entered into the contract of sale. Two cases where people were scalded by defective hot water bottles sold by pharmacists illustrate this. In one case the injury was suffered by the buyer who had gone into the shop to buy the hot water bottle. He was awarded damages under the Sale of Goods Act. In another case a father bought the hot water bottle but the injuries were suffered by his 7 year old daughter. She had no claim under the Act because she was not the buyer-and the father had no claim because he had not been injured. To obtain compensation the daughter had to look for a different legal principlè.

\section{Negligence}

This brings us to the other line of legal development. After some hesitation the courts eventually held, as recently as 1932, that a manufacturer owes to the ultimate consumer a duty to take reasonable care in making and putting up the product. Failure to take reasonable care is negligence and the person injured can sue, contract or no contract.

Under this principle the 7 year old girl scalded by the defective hot water bottle succeeded when she sued the manufacturer. The manufacturer could not explain how the defect came about, and in the absence of any explanation the court concluded that an employee must have been negligent.

When the claim is based not on a contract but on an allegation of negligence it is a defence to show that reasonable care was taken. The dairy whose milk was infected with typhoid bacteria would, it seems, have escaped liability if it had been sued for negligence rather than breach of the Sale of Goods Act. So the standards imposed under this head of the law are lower than those imposed under the sale contract.

A private patient who buys a medicine on prescription from a pharmacist enters into a contract of sale of goods with the pharmacist. Thus the pharmacist is liable under the Sale of Goods Act if the medicine is not of merchantable quality (if, for example, there was a manufacturing defect and the medicine causes injury). But if the pharmacist dispenses the identical medicine under a National Health Service prescription the Sale of Goods Act does not apply. There is no sale by the pharmacist to the patient and no contract between them. If the patient is injured as a result of a manufacturing defect a claim for compensation must rest on the proof of negligence. Since 
the pharmacist is unlikely to have been negligent in these circumstances (unless he ought to have spotted the defect), any claim is likely to be brought against the manufacturer.

\section{Strict liability}

These anomalies (which do not exist in every legal system) have given rise to influential calls for reform of the law, with a move towards the position found in French law and in the law of most parts of the United States as a result of judicial decisions. These jurisdictions hold the manufacturer under a strict liability to the ultimate consumer injured by the product.

In 1977 a report issued by the Law Commission for England and Wales and the Scottish Law Commission (two official bodies charged with the responsibility for eliminating anomalies from the law and for keeping it up to date) recommended that such a reform should be made, and a year later the Royal Commission on Civil Liability and Compensation for Personal Injury chaired by Lord Pearson, supported the recommendation. In Strasbourg in 1977 the Council of Europe adopted the European Convention on Products Liability, which sought to unify the laws of the different countries in Europe on the same lines (this convention has not yet come into force). And in 1976 the Commission of the European Communities issued its proposal for a Directive on Liability for Defective Products, which would require every member state of the European Economic Community to bring its law into line with the basic principle of strict liability for the manufacturer of defective products.

Various arguments have been adopted in support of the reform over and above the removal of the anomalies described above. Notably, it has been said that the question is essentially one of insurance. Not only is it cheaper for the manufacturer to insure against his possible liability (he is, if he is prudent, already insured against his liability for negligence) than for each consumer to take out an individual policy against the risk of being injured but also the manufacturer can, by regarding the insurance premium as a production cost, spread the cost of insurance across all purchasers of his products. Moreover, the liability creates an incentive to produce safer goods.

The proposals for reform do not distinguish between manufacturing and design defects. A manufacturing defect affects individual articles or batches of articles when the act of manufacture has gone wrong-as when cars leaving the production line between certain dates are recalled because of a failure to fix a particular component adequately. A design defect is when there is a flaw inherent in the product affecting all items. Thalidomide has been said to be an example of a design defect, though doctors may find this a curious way of describing the capacity of aspirin to cause gastric bleeding or of carbimazole to cause agranulocytosis. Whether these qualities would be regarded as defects at all is far from clear.

\section{Are drugs different?}

It has been urged that drugs are so different from other products that strict liability should not be imposed on their manufacturers. All drugs are potentially dangerous, they are capable of being misused, their defects canno always be foreseen, and sometimes it can seem that the "defect" is in the patient rather than in the drug. Moreover, the imposition of a greater liability might inhibit research and the production of new and valuable remedies. This view has gained only limited support outside the pharmaceutical and medical professions.

\section{No fault schemes}

Some countries, however, have established schemes whereby individuals injured by medicines may obtain compensation, even though no one was at fault, without having to claim against a particular manufacturer. Strict liability as described above also operates whether or not anyone was at fault, but the machinery contemplates a claim, ultimately backed up by a law suit, by the injured individual against the manufacturer. A no fault scheme entails the creation of a fund (whether administered by the government, by insurance companies, or by a group of manufacturers) against which claims may be made. The fund is administered independently of the particular manufacturer whose product was defective.

\section{Vaccine damage}

The United Kingdom does not have a general no fault scheme for medicinal injury, but it has implemented a system of compensation in a single limited area-namely, injury due to vaccines for certain listed diseases. The government was promoting a policy of administering to healthy young children a product-pertussis vaccine-that might not only prevent them from contracting an unpleasant and dangerous disease but which was also intended to protect children in general. When parents discovered that this policy, promoted for the general good, could also result in injury to their own healthy children (regardless of what might happen to these children and others should they happen to contract pertussis) they reacted with emotion and quickly built up political pressure to achieve the Vaccine Damage Payments Act 1980, which represents the only substantive recommendation of the Pearson royal commission to be implemented.

The Act had four important features:

(1) Compensation, up to a maximum of $£ 10000$, is payable only if the vaccine was used on a person aged under 18 years (except when vaccination was given at the time of an outbreak). Claims may be made only by children who survive over the age of 2 .

(2) Disablement (judged by a tribunal) must be at least $80 \%$.

(3) Causation must be shown on a balance of probabilities (that is the normal standard required in all civil litigation).

(4) Payment is made by the government, not by the manufacturer (this is a "no fault scheme").

Although the scheme has resulted in compensation for some claimants, many claims have been rejected by reason of the $80 \%$ disability rule or failure to prove that vaccination caused the injury on a balance of probabilities. This has led to some bitterness, with accusations that the tribunals were insensitive to human suffering and were applying the rules too restrictively, coupled with demands that borderline cases should be treated sympathetically-that is, that compensation should be awarded.

\section{Compensation for all?}

The truth is that wherever lines have to be drawn some cases will fall on one side of the line and some cases on the other. The tribunals were applying the rules by which they were bound as best they could. Attempts to provide compensation for one class but not another are bound to cause distress to those whose claims are denied.

Consider four children. A has a $90 \%$ disability caused by vaccination. B was vaccinated, suffered no ill effects as a result, but now has an identical $90 \%$ disability not caused by the vaccine. $C$ was not vaccinated and subsequently became $90 \%$ disabled by pertussis. $\mathrm{D}$ was born with a congenital $90 \%$ disability.

Of these four, only $A$ will receive compensation under the Vaccine Damage Payments Act. None of the others will qualify. Some people think that there is an inherent unreason in this result: suffering is being relieved according to cause rather than according to need. How the loss was suffered, they would say, is history; compensation should look to the future.

The decision to structure the fund in this way was political, and the unequal treatment of like disabilities is a course that seems to be demanded by the public. If it is not possible to provide for all the sick and disabled at the high level that a warm heart desires, the argument goes, compensation must be rationed. In consequence it becomes the aim of all potential claimants to seek to categorise themselves and their loved ones as specially deserving of a high level of resources, while at the same time expressing good will to those disabled by Act of God who do not qualify under any special programme and who will receive less.

\section{Strict liability: the defences}

There are thus two possible ways in which compensation for drug induced injury might be handled in the future. One is under the existing or reformed law of product liability. The other, which we explore in more detail, is by the creation of a new no fault scheme.

Where a claim for injury is based on negligence, and causation is proved on a balance of probabilities (as it always must be), the manufacturer may reply that the user was warned and knowingly took the risk on himself, or that the user himself behaved negligently. Whether a warning affords a defence to the manufacturer depends on many. factors, including the prominence given to it, the way it was expressed, and in particular whether it enabled the user to look after his safety while using the product as it was intended to be used. It is self evident that a manufacturer cannot protect himself against the consequences of his own negligence by a warning that "The maker may have been negligent. This product may be lethal. Use it at your own risk." Quite apart from warnings, however, the user's negligence does serve to reduce the manufacturer's liability. A court will apportion blame as between the parties and scale down the damages in proportion. These defences would also be available under the proposed regimens of strict liability. 
But a further defence, rejected by the law reformers, has been put forward by industry and espoused by the government. This is the defence that the manufacturer had developed the product to the highest current scientific standards and so should not be held responsible for what no one could prevent or foresee - the "state of the art" defence. In truth, such a defence is one of the distinctions between strict liability and negligence liability. To speak of strict liability with a state of the art defence is a contradiction in terms: one is speaking of negligence liability. The case of the typhoid bacteria in milk is a good example: we can class the dairy's liability as strict liability rather than liability for negligence precisely because the defence of state of the art was raised and rejected.

It is because the United Kingdom government has insisted on the introduction of the state of the art defence that the EEC discussions on the proposed directive have not yet come to fruition, for some EEC governments regard the defence as unacceptable.

\section{A scheme for drug induced injuries?}

The state of the art defence is clearly one which would be of particular relevance to drug induced injuries. Recent history has given us three examples, and indeed the demand for compensation for drug injury has stemmed chiefly from important accidents in which large numbers of people suffered major injuries or death due to a drug that has, as a consequence, been withdrawn. Thalidomide and clioquinol were given to people who had the expectation of a good life, and this was shattered. Practolol was used in angina pectoris, a disease that generally occurs in later life, but its consequences were to put an end to the capacities for enjoyment of those affected.

All three episodes were marked by major campaigns of groups of patients against the pharmaceutical companies who made the drugs. Two companies delayed paying compensation, while one (practolol) voluntarily set up an arrangement to compensate which, though criticised, was generally creditable. Of none of these companies could negligence be shown: indeed, the issue of negligence was not determined in the courts in any of these cases, and the issue of non-foreseeability would probably have negatived it.

In our view neither public demand nor public need is met by the expensive lottery of actions for negligence, and a regimen of strict liability (so called) with a state of the art defence would do no better. Something different is needed.

It is clear from experience that serious injuries may occur even in the absence of negligence. Among the possible reasons and circumstances are the following:

(1) There may be a defect in the manufacturing process by which the drug was made; the product is not what was intended (manufacturing defect). This might or might not be a result of negligence.

(2a) The drug has an inherent capacity to cause injury by its very nature; it continues in use because the overall benefits outweigh the inescapable risks ("design" defect).

(2b) A new drug is found, after grant of a product licence, to have such serious adverse effects that its use is no longer acceptable and it is withdrawn ("design" defect).

(3) The drug may be used unskilfully by the prescriber.

(4) The patient may not follow the instructions given.

(5) The patient may have an abnormality of his genetic constitution (idiosyncrasy) or disease which causes the drug to injure him.

(6) A person may be totally unaware that he is taking a serious risk, whether it be so extremely remote that he is not told-for example, sudden death from penicillin-or because circumstances prevent it, as in some cases of serious illness, including cancer.

(7) A person may know well that he is taking a serious risk and deliberately accept it, or, having been told of future risk, may give priority to present gain or convenience.

Any workable and just scheme must take all these possibilities into account and do so without a lot of hairsplitting.

In our view a no fault scheme offers the best prospect of a workable system to provide compensation for. drug injury. Since compensation is available from a central fund without proving fault it avoids the confrontation, delay, and expense of litigation. Compensation is divorced from questions of fault and liability (though we would not exclude the possibility of the fund seeking reimbursement from a manufacturer when appropriate).

A no fault scheme offers an administrative simplicity that litigation cannot provide. Causation must be proved, but once that is done compensation is payable.

Before describing how a no fault scheme could be made to work we examine the simple question why pharmaceutical companies should not be told by parliament that they must compensate people injured by their products and to get on with it.

\section{The obligation of industry}

When a drug is under development and goes into clinical trials sponsored by a company there is no doubt that the company should take responsibility for any injuries caused and, indeed, the Association of the British Pharmaceutical Industry has acknowledged this (Guidelines: Clinical TrialsCompensation for Medicine-induced Injury, 1983). We shall not further consider liability for injury occurring before the award of a product licence (marketing). But when a drug has a product licence-that is, is marketed-it has passed through rigorous official regulatory review and will be used in settings and patients of infinite variety.

Patients may take several drugs at a time, made by different companies; the drug causing the injury may not be identifiable or identifiable as made by a particular company; the company may deny causation, perhaps especially when the alleged drug injury mimics spontaneous disease (for instance, thromboembolism and oral contraceptives), so that the claimant has to go to the courts, which will also have great difficulty; the prescriber may have used the drug other than in strict accordance with the company's data sheet; the question of contributory negligence by the patient may cause the company to resist; the list of problems is endless. Despite the manifest and great difficulties, the interest of the pharmaceutical industry will best be served by the introduction of a scheme. Its reputation is seriously and continuously damaged by the absence of a scheme and it will remain under constant adverse criticism until this is remedied. The industry is known to be seriously concerned about its public image. It has expressed its willingness to discuss a scheme, but has also expressed its unwillingness to be left alone to find a scheme. We have sympathy with its position.

\section{A no fault scheme}

There should be a no fault scheme, and it should not be run by the pharmaceutical industry. The government cannot stand aside; indeed, we believe that the prime reason that the government seems to wish to stand aside is fear of the cost rather than because of any issue of principle.

A no fault scheme might work as follows:

(1) A central body (fund) should be set up (for finance, see below)

(2) The criteria for causation and for eligibility for compensation (see below) will be applied by a medical tribunal with legal and perhaps lay participation.

(3) If compensation is awarded then it can be paid at once, or at such time as the full (4tent of injury is determined.

(4) If it seems appropriate - that is, if negligence is suspected - then the central body will seek reimbursement from the body or person responsible (subrogation), but the injured person will not be involved. We regard the prevention of confrontations between patients and pharmaceutical companies as of paramount importance. The undoubted merits of this science based industry will continue to be overshadowed by criticism as long as such confrontations continue. It is very much in the interest of industry that a scheme should be implemented.

(5) There would be no difficulty in awarding compensation even though there was doubt about the origin of a particular medicine or when a succession of different brands or generic preparations had been used.

(6) Any scheme offering selective compensation for injury according to cause rather than according to need must require that causation should be proved according to the balance of probabilities. This latter is the criterion for civil law rather than "beyond reasonable doubt," which is the criterion of criminal law.

Inevitably there will be cases where the claimant will be totally convinced that he or she was injured by a drug and yet the medical tribunal will remain unpersuaded. There is no escape from this. Laxity or an excess of sympathy for a sad case will mean injustice and expenditure of scarce resources on people who are not intended to get special compensation and will deprive other disabled people. If society wants special schemes of compensation this will have to be accepted, for not to do so will make nonsense of selective schemes and broaden them into one big no fault scheme which society cannot perhaps afford (if it thought that it could afford such a scheme presumably it would have implemented it before now and there would be no need for the present discussion).

(7) The criteria generally proposed for judging eligibility for compensation are that the adverse event should carry a risk so remote that it would not ordinarily be taken into account when choosing the treatment, and the injury should be severe-for example, blood dyscrasias, hepatic necrosis, epidermal necrolysis. Whether or not a patient was warned would not be relevant. Negligence by the patient would be relevant, at least to some degree.

Injuries that would not normally be compensatable include high frequency serious effects-for example, of anticancer drugs, where a patient suffering from serious disease is taking serious risks to preserve life or escape serious disability.

Plainly there is room for much discussion, and there are plenty of areas of very rea difficulty - for example, where a drug increases the incidence of a spontaneous disease. But criteria such as the above have been in use in Sweden and other countries for years, and we should profit by their experience.

(8) It is necessary to draw substantial financial resources from somewhere. It is also necessary to get a proper balance between the interests of the individual, of industry, and of the professions. In the Federal Republic of Germany manufacturers are required to be insured and have found the cost surprisingly low so far. In Sweden pharmaceutical companies have undertaken liability and cover it with insurance. Premiums are related to company turnover.

In Britain, where drug prices are negotiated with government, it has been said by a minister of health that the cost of a compensation scheme sponsored by the industry would be taken into account in official price negotiations.

The possibility of a major catastrophe always remains, and should this happen it would be impossible for the government to stand by when a well constructed insurance
W 
scheme failed. We do not believe arguments over provision for a remote and enormous catastrophe should inhibit the introduction of a general scheme.

The climate of opinion is changing. The inevitability of some such scheme is increasingly being accepted. We believe that discussions on financing a scheme should be opened between the principally interested parties with the aim of producing a scheme that is so obviously workable and in the public interest that the government will not wish to, indeed cannot, stand aside.

\section{Conclusion}

We believe that we have said enough to show that, failing a comprehensive compensation scheme for all the misfortunes of life, a no fault scheme for drug induced injury is desirable, workable, and need not cost so much as to render serious discussion on implementation a waste of time.

Schemes already operate in other countries and much can be learnt from them. No doubt none of them is perfect, but they show that critics who spend their time on the easy art of proving that the difficulties are too great to contemplate action are wrong.

We consider that the principal interested parties should get together to propose a scheme which, after wide consultation, should formally be put forward. This should be done without waiting for the government to act, though ultimately government, and perhaps parliamentary, approval will be necessary.

This article is an abridged version of a chapter to be included in Iatrogenic Diseases, third edition, edited by J P Griffin and P F D'Arcy, and is published by permission of Oxford University Press.

\title{
Needs and Opportunities in Rehabilitation
}

\section{Severe disability: 2-Residential care and living in the community}

\author{
DAPHNE GLOAG
}

Disability has been defined as a restriction or lack of ability in normal activities resulting from an impairment, and handicap as the resulting social disadvantage. ${ }^{12}$ Some argue that disability is imposed by the material environment and the attitudes of society on those with physical impairments (see box), and is eliminated once people are reintegrated into society. ${ }^{3}$ Others have spoken of "the diminishing of personal authority [being] itself disabling." 4

Clearly, however, disabled people are not a homogeneous group and there are very different needs and capabilities. There may be medical, social, or psychological problems, or all three. Some have no medical problems (notably many with spinal injuries) and these people on the whole should be living in the community. At the other extreme are patients severely affected by stroke and multiple sclerosis, for example, with difficult medical afflictions requiring 24 hour nursing care that is usually impracticable at home. In between are those with dementia or other mental impairment, who appear in many different settings (including at home with distracted and often unsupported families), and those with behaviour disturbances associated often with brain damage, for whom there is little adequate provision (see below). And, finally, there are people with moderate disabilities who need residential care largely for "social" reasons: if they are difficult and no one will fight to keep them in the community, or if they themselves want to give up the struggle for independence or need companionship.

Long term care and sometimes shorter term and intermittent care are provided by NHS units for the younger disabled, local authority homes, and voluntary homes, including the Royal Hospital and Home for Incurables and the Royal Star and Garter Home, which can cope with those needing a lot of nursing as well-as rehabilitation. Living in the community may be possible with professional and voluntary support and sophisticated aids in a person's own home

British Medical Journal, Loedon WC1H 9JR

DAPHNE GLOAG, MA, staff editor and through various types of group living and sheltered accommodation schemes; some agencies provide a range of options from full residential care to independent housing.

\section{Residential care}

Writing in 1970, Miller and Gwynne say that the task of institutions in practice is "to cater for the socially dead during the interval between social death and physical death." Though this is still true for many residents, ideas and practices have changed a lot since then. Entering an institution is now much less the point of no return they saw it as, and flexibility is one of the most important features of the present scene. I have heard of people leaving even after years in a home. Commonly now a home or special unit is a medium term stopgap or transition house preparing some of its residents for the community and allowing a breathing space while a more permanent solution is being worked out. Short spells of residential care, especially to give relatives a break or to provide rehabilitation, are favoured, and crises such as family illness or marriage breakdown may also demand a refuge. A conference on this "dynamic approach" looked at the different patterns of care and of opportunities for independent living in a European context. ${ }^{6}$

"Ideally residential care," say Dartington et $a l, 4$ "is about providing a space in which disabled people are free to realise their potential," and it is helpful to look at different settings of care from this point of view. The "warehousing" or custodial and the "horticultural" or developmental models of care described by Miller and Gwynne are still valid, and so is their conclusion that everyone should have "the right to choose dependency, or to take advantage of developmental opportunities. It then becomes the task of the institution first to help the individual make this decision and second to provide him with the facilities to implement it."s The right environment for privacy, independence, and autonomy was not easily provided in the 10 residential homes-NHS, local authority, and voluntary-studied in depth in 1979 in a DHSS survey (reported by $\mathbf{H}$ Canter to the Medical Disability Society, December 1984). But it appeared easier to hand responsibility over to residents in a voluntary home because of the simpler management 